\title{
The Contribution of Matrix Metalloproteinase-8 Promoter Polymorphism to Oral Cancer Susceptibility
}

\author{
YI-WEN HUNG $^{1 *}$, CHIA-WEN TSAI $^{2,3^{*}}$, CHENG-NAN WU $^{2 *}$, LIANG-CHUN SHIH $^{4,5}$, YEN-YU CHEN $^{3}$, \\ YEN-FANG LIU ${ }^{3}$, HUEY-SHAN HUNG ${ }^{4}$, MING-YI SHEN ${ }^{4}$, WEN-SHIN CHANG ${ }^{3}$ and DA-TIAN BAU $3,4,6$ \\ ${ }^{1}$ Department of Medicine Research, Taichung Veterans General Hospital, Taichung, Taiwan, R.O.C.; \\ ${ }^{2}$ Department of Medical Laboratory Science and Biotechnology, \\ Central Taiwan University of Science and Technology, Taichung, Taiwan, R.O.C.; \\ ${ }^{3}$ Terry Fox Cancer Research Laboratory, China Medical University Hospital, Taichung, Taiwan, R.O.C.; \\ ${ }^{4}$ Graduate Institute of Biomedical Sciences, China Medical University, Taichung, Taiwan, R.O.C.; \\ ${ }^{5}$ Department of Otolaryngology, China Medical University Hospital, Taichung, Taiwan, R.O.C.; \\ ${ }^{6}$ Department of Bioinformatics and Medical Engineering, Asia University, Taichung, Taiwan, R.O.C.
}

\begin{abstract}
Background/Aim: Metalloproteinases (MMPs) are a family of multifunctional proteins reported to be overexpressed in several types of cancers. However, the contribution of MMP8 genotype to oral cancer has not been elucidated. In this study, we focused on the contribution of polymorphisms in the promoter region of MMP-8 (C-799T) and two non-synonymous polymorphisms (Val436Ala and Lys460Thr) to Taiwanese oral cancer. Materials and Methods: In this case-control study, MMP-8 genotype, was examined among 788 patients with oral cancer and 956 gender-and age-matched healthy controls regarding its potential to determine oral cancer risk. Results: The distributions of MMP-8 C-799T, Val436Ala and Lys460Thr genotypes were not different between the oral cancer and non-cancer control groups. We also analyzed the allelic frequency distributions and no significant difference was found. As for geneenvironment interaction analysis, there was an increased risk for smokers, alcohol drinkers or betel quid chewers with variant MMP-8 C-799T or Val436Ala genotypes. Conclusion: Our findings suggest that the polymorphisms at MMP-8 C7997 or Val436Ala may not play a major role in mediating
\end{abstract}

This article is freely accessible online.

*These Authors contributed equally to this study.

Correspondence to: Da-Tian Bau, Terry Fox Cancer Research Laboratory, China Medical University Hospital, 2 Yuh-Der Road, Taichung, 404 Taiwan, R.O.C. Tel: +886 422052121 (Ext. 7534), e-mail: datian@mail.cmuh.org.tw; artbau2@gmail.com

Key Words: Genotype, MMP-8, oral cancer, polymerase chain reaction, polymorphism. personal risk of oral cancer; however, the detailed mechanisms require further investigation.

Oral cancer is the eighth most commonly diagnosed cancer worldwide and has the highest male incidence density in Taiwan (1-3). There is regional variation in trends of oral cancer around the world, depending on the etiology and the risk factors involved. According to the government annual report, oral cancer is the fourth cause of cancer-related death among males in Taiwan and has been reported to be closely associated with tobacco, alcohol and betel nut consumption habits (4-7). In the past years, genomic biomarkers for oral cancer in Taiwan have been revealed (8-14) and further cellular etiological investigations and the interactions among the genetic and lifestyle factors will contribute to personalized cancer early detection and therapy.

Matrix metalloproteinases (MMPs), also known as matrixins, are a family of calcium-dependent zinc-containing endopeptidases that play a key role in extracellular matrix homeostasis controlling the degradation of the components of connective tissue matrices $(15,16)$. In carcinogenesis, MMPs and their inhibitors are also related to the regulation of oral cancer invasion and metastasis (17-20). The imbalance of these MMPs and their interactions with specific inhibitors, e.g. the tissue inhibitors of metalloproteinases (TIMPs), may contribute to the initiation and progression of cancer $(16,17,21)$. MMP-8, originally known as neutrophil collagenase, is expressed in not only neutrophils but also epithelial cells, fibroblasts, macrophages and endothelial cells (22-24). In recent years, mounting evidence showed that MMP-8 was capable to conduct cancer- and metastasissuppressive activities. Firstly, knockout of $M M P$ induced a dramatic increase in the incidence of carcinogen-induced 
skin papillomas among a male mouse model (25). Secondly, in two cell lines derived from wild-type MDA-MB-435 cancer cells, which display high (M-4A4) or low (NM-2C5) metastatic capacities, overexpression of MMP-8 would reduce the metastatic capacity of M-4A4 cells, whereas knockdown of $M M P-8$ gene would enhance the metastatic capacity of NM-2C5 cells $(26,27)$. Thirdly, the rs 11225395 C-799T single-nucleotide polymorphism (SNP) at the MMP8 promoter region may affect the expression levels of MMP-8 and associate with early-stage disease (28). Fourthly, higher $M M P 8$ mRNA levels in primary breast cancers are associated with reduced lymph node metastasis and with improved relapse-free and overall survival in nodenegative patients (29).

As for oral cancer, high MMP-8 expression level has been reported to be protective in human tongue cancer and in a carcinogen-induced mice model (30). However, the genomic contribution of $M M P-8$ to oral cancer has not been elucidated. In the current study, we aimed to reveal the contributions of MMP-8 C-799T, Val436Ala and Lys460Thr genotypes to the risk of oral cancer in the Taiwanese population.

\section{Materials and Methods}

Investigated population. The current study was approved by the Institutional Review Board of the China Medical University Hospital (DMR101-IRB 1-306) and written-informed consent has been obtained from all the participants. Totally, seven hundred and eighty-eight patients diagnosed with oral cancer were recruited at the China Medical University Hospital in central Taiwan. All patients voluntarily participated completed a self-administered questionnaire and willingly provided $5 \mathrm{ml}$ of their peripheral blood. The questionnaire administered to participants included questions on history and frequency of alcohol consumption, areca chewing and smoking habits. Self-reported alcohol consumption, areca chewing and smoking habits were evaluated and classified as categorical variables. Information on these factors was obtained as more than twice a week for years as "ever". A total of 956 noncancer healthy individuals as controls were selected by matching for age and gender after initial random sampling from the Health Examination Cohort of the Hospital. The male versus female ratio was $76 \%$ to $24 \%$ in each group. The mean age of the patients and the controls was 55.8 (standard deviation $(\mathrm{SD})=9.9$ ) and 56.6 $(\mathrm{SD}=8.7)$ years, respectively. More detailed demographic information is summarized in Table I.

Genotyping conditions. Genomic DNA from the peripheral blood leucocytes of each participant was prepared applying the QIAamp Blood Mini Kit (Blossom, Taipei, Taiwan) and stored at $-80^{\circ} \mathrm{C}$ until processed as per our previous standard procedure (31-33). The sequences of primers and the restriction enzymes for $M M P-8$ genotyping are designed by Terry Fox Cancer Research Lab and summarized in Table II. The polymerase chain reaction (PCR) cycling conditions were: one cycle at $94^{\circ} \mathrm{C}$ for $5 \mathrm{~min} ; 35$ cycles of $94^{\circ} \mathrm{C}$ for $30 \mathrm{~s}, 57^{\circ} \mathrm{C}$ for $30 \mathrm{~s}$ and $72^{\circ} \mathrm{C}$ for $30 \mathrm{~s}$; and a final extension at $72^{\circ} \mathrm{C}$ for $10 \mathrm{~min}$. After amplification, PCR products were subjected to digestion by restriction endonuclease for $2 \mathrm{~h}$ and separation using 3\% agarose gel electrophoresis. All the genotypic processing was repeated blindly by two researchers independently, with results being $100 \%$ concordant.

Statistical analyses. Student's $t$-test was used for the comparison of ages between the case and the control groups. Pearson's Chi-square test was used to compare the distribution of the $M M P-8$ genotypes among the subgroups. The associations between the $M M P-8$ genotypes and oral cancer risk were estimated by computing odds ratios (ORs) and their 95\% confidence intervals (CIs) from logistic regression analysis. Any difference at $p<0.05$ was considered statistically significant.

\section{Results}

The frequency distributions of demographic characters, including age, gender, personal habits and primary tumor sites for the 788 patients with oral cancer and 956 noncancer controls, are summarized and statistically compared in Table I. There was no difference in the distributions of age and gender between the control and case groups since we have applied the frequency matching methodology in recruiting the non-cancer healthy controls (Table I). Among the investigated large individuals, it was found that betel quid chewers and smokers were of higher percentages in patients with oral cancer than in the controls (Table I). Thus, smoking and betel quid chewing may be the risk behavioral factors for oral cancer in Taiwan. Clinically, most of the primary tumors occurred in the tongue and buccal mucosa (Table I).

The distributions of the MMP- 8 C-799T, Val436Ala and Lys460Thr genotypes among the non-cancer controls and the oral cancer patients are presented and statistically analyzed in Table III. First, there were no polymorphic genotype at MMP-8 Val436Ala found among either the oral cancer cases or the non-cancer controls of Taiwan. All the subjects were of TT genotype at MMP-8 Val436Ala (Table III, bottom panel). Second, the ORs with adjusting those possible confounding factors (age, gender and smoking status) for the people carrying variant $\mathrm{CT}$ and TT genotypes at $M M P-8$ promoter $\mathrm{C}-799 \mathrm{~T}$ were $0.89(95 \% \mathrm{CI}=0.67-1.21, p=0.1060)$ and 0.82 (95\% CI=0.61-1.30, $p=0.0776)$, respectively, compared to those carrying the CC wild-type genotype (Table II, top panel). The $\mathrm{p}$ for trend was not significant ( $p=0.2476)$ (Table III). In the dominant model (CT plus TT versus $\mathrm{CC}$ ), the association between $M M P-8$ promoter $\mathrm{C}$ 799T polymorphism and the risk for oral cancer was still not statistically significant (adjusted $\mathrm{OR}=0.84,95 \% \mathrm{CI}=0.68$ $1.22, p=0.0547$ ) (Table III, upper panel). Third, a very small percentage of Taiwanese people was of AC genotype at $M M P-8$ Lys460Thr without any homo-variant $(0.9 \%$ and $0.6 \%$ in oral cancer patient and control groups, respectively), while there was no association between $M M P-8$ Lys460Thr 
Table I. Characteristics of the 788 patients with oral cancer and 956 controls investigated.

\begin{tabular}{|c|c|c|c|c|c|c|c|}
\hline \multirow[t]{2}{*}{ Characteristic } & \multicolumn{3}{|c|}{ Controls ( $\mathrm{n}=956)$} & \multicolumn{3}{|c|}{ Cases $(n=788)$} & \multirow[t]{2}{*}{$p$-Value ${ }^{a}$} \\
\hline & $\mathrm{n}$ & $\%$ & Mean (SD) & $\mathrm{n}$ & $\%$ & Mean (SD) & \\
\hline Age (years) & & & $56.6(8.7)$ & & & $55.8(9.9)$ & 0.7951 \\
\hline Gender & & & & & & & 1.0000 \\
\hline Male & 727 & $76.0 \%$ & & 599 & $76.0 \%$ & & \\
\hline Female & 229 & $24.0 \%$ & & 189 & $24.0 \%$ & & \\
\hline \multicolumn{8}{|l|}{ Personal habits } \\
\hline Areca chewing & 506 & $52.9 \%$ & & 661 & $83.9 \%$ & & $<0.0001 *$ \\
\hline Cigarette smoking & 667 & $69.8 \%$ & & 595 & $75.5 \%$ & & $0.0084^{*}$ \\
\hline Alcohol drinking & 641 & $67.1 \%$ & & 560 & $71.1 \%$ & & 0.0773 \\
\hline \multicolumn{8}{|l|}{ Primary tumor site } \\
\hline Tongue & & & & 325 & $41.2 \%$ & & \\
\hline Buccal mucosa & & & & 294 & $37.3 \%$ & & \\
\hline Mouth floor & & & & 30 & $3.8 \%$ & & \\
\hline Retromolar trigone & & & & 26 & $3.3 \%$ & & \\
\hline Alveolar ridge & & & & 18 & $2.3 \%$ & & \\
\hline Palate & & & & 18 & $2.3 \%$ & & \\
\hline Lip & & & & 39 & $4.9 \%$ & & \\
\hline Others & & & & 38 & $4.9 \%$ & & \\
\hline
\end{tabular}

$\mathrm{SD}$, Standard deviation; abased on Chi-square test; *statistically significant $(p<0.05)$.

Table II. Summary of primer sequences, specific restriction enzymes, digestion conditions, PCR and digestion product sizes.

\begin{tabular}{|c|c|c|c|c|}
\hline Polymorphism (rs number) & Primer sequences & Restriction enzyme & SNP sequence & DNA fragment size (bp) \\
\hline C-799T & F: 5'-CCATCTTCACATAGCCTTGG-3' & $S f c \mathrm{I}$ & $\mathrm{T}$ & $285 \mathrm{bp}$ \\
\hline$(\mathrm{rs} 11225395)$ & R: 5'-CCTTGTCTTCTGCCTGTGAA-3' & & $\mathrm{C}$ & $172+113 \mathrm{bp}$ \\
\hline Lys460Thr & F: 5'-GGATTACAGGCATTAGCCAC-3' & Nla III & A & $332 \mathrm{bp}$ \\
\hline$(\mathrm{rs} 35866072)$ & R: 5'-CGAAAATGCATGCTGAACTTCC-3' & & $\mathrm{C}$ & $245+87 \mathrm{bp}$ \\
\hline Val436Ala & F: 5'-GGATTACAGGCATTAGCCAC-3' & $B b s \mathrm{I}$ & $\mathrm{C}$ & $264 \mathrm{bp}$ \\
\hline$(\mathrm{rs} 34009635)$ & R: 5'-GCCATATCTACAGTTAAGCCAT-3' & & $\mathrm{T}$ & $162+102 \mathrm{bp}$ \\
\hline
\end{tabular}

PCR, Polymerase chain reaction; SNP, singe-nucleotide polymorphism; F, forward primer; R, reverse primer; bp, base-pairs.

genotypes and the risk for oral cancer (adjusted $\mathrm{OR}=0.86$, 95\% CI=0.41-5.94, $p=0.3693$ ) (Table III, medium panel). To sum up, these data indicated that neither $M M P-8$ promoter C-799T nor Lys460Thr genotypes may play a major role for determining the risk of oral cancer in Taiwan (Table III).

To confirm the findings of Table III, analysis of allelic frequency distribution for $M M P-8$ was also conducted, with the results being summarized in Table IV. The results showed that the adjusted OR for subjects carrying the $\mathrm{T}$ allele at $M M P-8$ promoter $\mathrm{C}-799 \mathrm{~T}$ was 0.83 (95\% $\mathrm{CI}=0.77-1.41$, $p=0.0776$ ), compared to those carrying the $\mathrm{C}$ wild-type allele (Table IV). Supporting the findings in Table III, there is no differential distribution of allelic frequencies between oral cancer patient and non-cancer control groups regarding the $M M P-8$ promoter C-799T or Lys460Thr (Table IV).
Last, we examined the interactions among the genotype of $M M P-8$ and behavioral factors, including personal cigarette smoking, betel quid chewing and alcohol drinking habits. There was not any interaction of MMP-8 C-799T and Val436Ala genotype with cigarette smoking, betel quid chewing and alcohol drinking habits (data not shown).

\section{Discussion}

In the literature, the genotypes at promoters' SNPs of $M M P$ genes were found to be associated with the risk of several types of cancers $(8,34-40)$; however, no work has examined the polymorphisms in $M M P-8$ as risk factors for oral cancer. In the present study, we firstly evaluated the contribution of MMP-8 C-799T, Val436Ala and Lys460Thr genotypes to oral 
in vivo $31: 585-590(2017)$

Table III. Distributions of matrix metalloproteinas-8 (MMP-8) genotypic frequencies among the oral cancer cases and controls.

\begin{tabular}{|c|c|c|c|c|}
\hline & Cases $(\%)$ & Controls (\%) & Adjusted OR $(95 \% \mathrm{CI})^{\mathrm{a}}$ & $p$-Value ${ }^{b}$ \\
\hline \multicolumn{5}{|l|}{ C-799T } \\
\hline $\mathrm{CC}$ & $414(52.5)$ & $466(48.7)$ & 1.00 (reference) & \\
\hline $\mathrm{CT}$ & $284(36.1)$ & $364(38.1)$ & $0.89(0.67-1.21)$ & 0.1060 \\
\hline TT & $90(11.4)$ & $126(13.2)$ & $0.82(0.61-1.30)$ & 0.0776 \\
\hline $\mathrm{CT}+\mathrm{TT}$ & $374(47.5)$ & $490(51.3)$ & $0.84(0.68-1.22)$ & 0.0547 \\
\hline $\begin{array}{l}p_{\text {trend }} \\
\text { Lys460Thr }\end{array}$ & & & & 0.2476 \\
\hline AA & $781(99.1)$ & $946(99.4)$ & 1.00 (reference) & \\
\hline $\mathrm{AC}$ & $7(0.9)$ & $10(0.6)$ & $0.86(0.41-5.94)$ & 0.3693 \\
\hline $\mathrm{CC}$ & $0(0.0)$ & $0(0.0)$ & -- & \\
\hline \multicolumn{5}{|l|}{ Val436Ala } \\
\hline TT & $788(100.0)$ & $956(100.0)$ & 1.00 (reference) & \\
\hline $\mathrm{CT}$ & $0(0.0)$ & $0(0.0)$ & -- & \\
\hline $\mathrm{CC}$ & $0(0.0)$ & $0(0.0)$ & -- & \\
\hline$p_{\text {trend }}$ & & & & \\
\hline
\end{tabular}

OR, Odds ratio; CI, confidence interval. aData have been adjusted with confounding factors that include age, gender, smoking, alcohol drinking and betel quid chewing status. bBased on Chi-square test without Yates' correction; * $p<0.05$.

Table IV. Allelic frequencies for matrix metalloproteinas-8 (MMP-8) polymorphisms in the oral cancer and control groups.

\begin{tabular}{|c|c|c|c|c|}
\hline Polymorphic site allele & $\begin{array}{c}\text { Cases }(\%) \\
n=716\end{array}$ & $\begin{array}{c}\text { Controls }(\%) \\
n=1432\end{array}$ & $\begin{array}{l}\text { Adjusted OR } \\
(95 \% \mathrm{CI})^{\mathrm{a}}\end{array}$ & $p$-Value \\
\hline \multicolumn{5}{|l|}{ C-799T } \\
\hline Allele C & $1112(70.6)$ & $1296(67.8)$ & 1.00 (reference) & 0.0776 \\
\hline Allele T & $464(29.4)$ & $616(32.2)$ & $0.83(0.77-1.41)$ & \\
\hline \multicolumn{5}{|l|}{ Lys460Thr } \\
\hline Allele A & 1569 (99.6) & 1902 (99.5) & 1.00 (reference) & 0.3696 \\
\hline Allele C & $7(0.4)$ & $10(0.5)$ & $0.89(0.43-6.37)$ & \\
\hline \multicolumn{5}{|l|}{ Val436Ala } \\
\hline Allele T & $716(100.0)$ & $1432(100.0)$ & 1.00 (reference) & \\
\hline Allele C & $0(0.0)$ & $0(0.0)$ & -- & \\
\hline
\end{tabular}

OR, Odds ratio; CI, confidence interval. a Data have been adjusted with confounding factors that include age, gender, smoking, alcohol drinking and betel quid chewing status. bBased on Chi-square test without Yates' correction; * $p<0.05$.

cancer risk and their interactions with alcohol drinking, cigarette smoking and areca chewing among Taiwanese people. The results showed that neither the genotypic nor the allelic frequencies of $M M P-8$ C-799T, Val436Ala and Lys460Thr were differentially distributed among the patients and non-cancer healthy controls (Tables III and IV).

This is the first study to reveal an interaction between MMP1 1607 genotype and cigarette smoking on the susceptibility to oral cancer. Long-term tobacco smoking and areca chewing have been shown to contribute to etiology of oral cancer development $(9,10,41-44)$. The results showed that gene-environment interaction was not obvious between $M M P-8$ genotypes and personal risk behaviors, alcohol drinking, cigarette smoking or areca chewing. However, the mechanisms are very complex and need more research. In Table I, it can be seen that a higher proportion of individuals had consumed areca, cigarettes and alcohol in the group of patients with oral cancer than the controls (Table I).

In conclusion, this is the first study to examine the role of $M M P-8$ promoter together with non-synonymous polymorphic genotypes in oral cancer susceptibility. Our findings suggested that the variant genotypes at promoter region C-799T and non-synonymous Val436Ala or Lys460Thr of $M M P-8$ do not significantly confer susceptibility to oral cancer in the Taiwanese population. 
Further multi-center and multi-population studies for the genotypes of other members of the MMP family and their contribution to oral cancer susceptibility have to be undertaken.

\section{Acknowledgements}

The Authors declare no conflict of interest in regard to this study The Authors appreciate the Tissue-bank of China Medical University Hospital for their excellent technical assistance. This study was supported mainly by the Taiwan Ministry of Science and Technology to Professor Bau (MOST-104-2320-B-039-036 and MOST-105-2320-B-039-038) and partially by research grant from Taiwan Ministry of Health and Welfare Clinical Trial and Research Center of Excellence (MOHW106-TDU-B-212-113004) and Taichung Veterans General Hospital (TCVGH-CTUST1067701) for Dr. Hung.

\section{References}

1 Siegel RL, Miller KD and Jemal A: Cancer Statistics, 2017. CA Cancer J Clin 67: 7-30, 2017.

2 Miller KD, Siegel RL, Lin CC, Mariotto AB, Kramer JL, Rowland JH, Stein KD, Alteri R and Jemal A: Cancer treatment and survivorship statistics, 2016. CA Cancer J Clin 66: 271-289, 2016.

3 Siegel RL, Miller KD and Jemal A: Cancer statistics, 2016. CA Cancer J Clin 66: 7-30, 2016.

4 Taiwan: Cancer Registration System Annual Report. Department of Health, Taiwan, 2015.

5 Chung $\mathrm{CH}$, Yang YH, Wang TY, Shieh TY and Warnakulasuriya S: Oral precancerous disorders associated with areca quid chewing, smoking, and alcohol drinking in southern Taiwan. J Oral Pathol Med 34: 460-466, 2005.

6 Lee CH, Ko YC, Huang HL, Chao YY, Tsai CC, Shieh TY and Lin LM: The precancer risk of betel quid chewing, tobacco use and alcohol consumption in oral leukoplakia and oral submucous fibrosis in southern Taiwan. Br J Cancer 88: 366-372, 2003.

7 Chen PC, Kuo C, Pan CC and Chou MY: Risk of oral cancer associated with human papillomavirus infection, betel quid chewing, and cigarette smoking in Taiwan--an integrated molecular and epidemiological study of 58 cases. J Oral Pathol Med 31: 317-322, 2002.

8 Sun KT, Tsai CW, Chang WS, Shih LC, Chen LY, Tsai MH, Ji HX, Hsiao CL, Liu YC, Li CY and Bau DT: The contribution of matrix metalloproteinase-1 genotype to oral cancer susceptibility in Taiwan. In Vivo 30: 439-444, 2016.

9 Tsai CW, Chang WS, Lin KC, Shih LC, Tsai MH, Hsiao CL, Yang MD, Lin CC and Bau DT: Significant association of Interleukin-10 genotypes and oral cancer susceptibility in Taiwan. Anticancer Res 34: 3731-3737, 2014.

10 Tsai CW, Chang WS, Liu JC, Tsai MH, Lin CC and Bau DT: Contribution of DNA double-strand break repair gene XRCC3 genotypes to oral cancer susceptibility in Taiwan. Anticancer Res 34: 2951-2956, 2014.

11 Tsai CW, Tsai MH, Tsou YA, Shih LC, Tseng HC, Chang WS, Ho CY, Lee HZ and Bau DT: The joint effect of smoking and hOGG1 genotype on oral cancer in Taiwan. Anticancer Res 32: 3799-3803, 2012
12 Bau DT, Tsai CW, Lin CC, Tsai RY and Tsai MH: Association of alpha B-crystallin genotypes with oral cancer susceptibility, survival, and recurrence in Taiwan. PLoS One 6: e16374, 2011.

13 Tsai CW, Hsu CF, Tsai MH, Tsou YA, Hua CH, Chang WS, Lin $\mathrm{CC}$ and Bau DT: Methylenetetrahydrofolate reductase (MTHFR) genotype, smoking habit, metastasis and oral cancer in Taiwan. Anticancer Res 31: 2395-2399, 2011.

14 Bau DT, Tsai MH, Tsou YA, Wang CH, Tsai CW, Sun SS, Hua $\mathrm{CH}$, Shyue SK and Tsai RY: The association of caveolin-1 genotypes with oral cancer susceptibility in Taiwan. Ann Surg Oncol 18: 1431-1438, 2011.

15 Woessner JF Jr.: Matrix metalloproteinases and their inhibitors in connective tissue remodeling. FASEB J 5: 2145-2154, 1991.

16 Murphy G and Docherty AJ: The matrix metalloproteinases and their inhibitors. Am J Respir Cell Mol Biol 7: 120-125, 1992.

17 Singh RD, Haridas N, Patel JB, Shah FD, Shukla SN, Shah PM and Patel PS: Matrix metalloproteinases and their inhibitors: Correlation with invasion and metastasis in oral cancer. Indian J Clin Biochem 25: 250-259, 2010.

18 Yang MD, Chang WS, Tsai CW, Wang MF, Chan YC, Chan KC, Lu MC, Kao AW, Hsu CM and Bau DT: Inhibitory effects of AVEMAR on proliferation and metastasis of oral cancer cells. Nutr Cancer 68: 473-480, 2016.

19 Huang SH, Law CH, Kuo PH, Hu RY, Yang CC, Chung TW, Li JM, Lin LH, Liu YC, Liao EC, Tsai YT, Wei YS, Lin CC, Chang CW, Chou HC, Wang WC, Chang MD, Wang LH, Kung HJ, Chan HL and Lyu PC: MMP-13 is involved in oral cancer cell metastasis. Oncotarget 7: 17144-17161, 2016.

20 Ahmed Haji Omar A, Haglund C, Virolainen S, Hayry V, Atula T, Kontio R, Salo T, Sorsa T and Hagstrom J: MMP-7, MMP-8, and MMP-9 in oral and cutaneous squamous cell carcinomas. Oral Surg Oral Med Oral Pathol Oral Radiol 119: 459-467, 2015.

21 Kessenbrock K, Plaks V and Werb Z: Matrix metalloproteinases: Regulators of the tumor microenvironment. Cell 141: 52-67, 2010.

22 Van Lint $\mathrm{P}$ and Libert C: Matrix metalloproteinase-8: Cleavage can be decisive. Cytokine Growth Factor Rev 17: 217-223, 2006.

23 Kuropkat C, Duenne AA, Herz U, Renz H and Werner JA: Significant correlation of matrix metalloproteinase and macrophage colony-stimulating factor serum concentrations in patients with head and neck cancer. Neoplasma 51: 375-378, 2004.

24 Quintero PA, Knolle MD, Cala LF, Zhuang Y and Owen CA: Matrix metalloproteinase-8 inactivates macrophage inflammatory protein-1 alpha to reduce acute lung inflammation and injury in mice. J Immunol 184: 1575-1588, 2010.

25 Balbin M, Fueyo A, Tester AM, Pendas AM, Pitiot AS, Astudillo A, Overall CM, Shapiro SD and Lopez-Otin C: Loss of collagenase- 2 confers increased skin tumor susceptibility to male mice. Nat Genet 35: 252-257, 2003.

26 Montel V, Kleeman J, Agarwal D, Spinella D, Kawai K and Tarin D: Altered metastatic behavior of human breast cancer cells after experimental manipulation of matrix metalloproteinase 8 gene expression. Cancer Res 64: 1687-1694, 2004.

27 Agarwal D, Goodison S, Nicholson B, Tarin D and Urquidi V: Expression of matrix metalloproteinase 8 (MMP-8) and tyrosinase-related protein-1 (TYRP-1) correlates with the absence of metastasis in an isogenic human breast cancer model. Differentiation 71: 114-125, 2003. 
28 Decock J, Long JR, Laxton RC, Shu XO, Hodgkinson C, Hendrickx W, Pearce EG, Gao YT, Pereira AC, Paridaens R, Zheng $\mathrm{W}$ and Ye S: Association of matrix metalloproteinase-8 gene variation with breast cancer prognosis. Cancer Res 67: 10214-10221, 2007.

29 Gutierrez-Fernandez A, Fueyo A, Folgueras AR, Garabaya C, Pennington CJ, Pilgrim S, Edwards DR, Holliday DL, Jones JL, Span PN, Sweep FC, Puente XS and Lopez-Otin C: Matrix metalloproteinase-8 functions as a metastasis suppressor through modulation of tumor cell adhesion and invasion. Cancer Res 68 : 2755-2763, 2008.

30 Korpi JT, Kervinen V, Maklin H, Vaananen A, Lahtinen M, Laara E, Ristimaki A, Thomas G, Ylipalosaari M, Astrom P, Lopez-Otin C, Sorsa T, Kantola S, Pirila E and Salo T: Collagenase-2 (matrix metalloproteinase-8) plays a protective role in tongue cancer. Br J Cancer 98: 766-775, 2008.

31 Lai YL, Gong CL, Fu CK, Yueh TC, Tsai CW, Chang WS, Hsiao CL, Yen ST, Li HT, Jeng LB, Wang SC and Bau DT: The contribution of matrix metalloproteinase-1 genotypes to hepatocellular carcinoma susceptibility in Taiwan. Cancer Genomics Proteomics 14: 119-125, 2017.

32 Pei JS, Hsu PC, Chou AK, Tsai CW, Chang WS, Hsiao CL, Hsu YN, Cheng SP and Bau DT: Matrix metalloproteinase-1 genotype contributes to the risk of non-solid tumor in childhood leukemia. Anticancer Res 36: 5127-5132, 2016.

33 Pei JS, Chang WS, Hsu PC, Tsai CW, Hsu CM, Ji HX, Hsiao $\mathrm{CL}, \mathrm{Hsu}$ YN and Bau DT: The association of flap endonuclease 1 genotypes with the risk of childhood leukemia. Cancer Genomics Proteomics 13: 69-74, 2016.

34 Tsai CW, Chang WS, Gong CL, Shih LC, Chen LY, Lin EY, Li HT, Yen ST, Wu CN and Bau DT: Contribution of matrix metallopeptidase-1 genotypes, smoking, alcohol drinking and areca chewing to nasopharyngeal carcinoma susceptibility. Anticancer Res 36: 3335-3340, 2016.

35 Ye S: Polymorphism in matrix metalloproteinase gene promoters: Implication in regulation of gene expression and susceptibility of various diseases. Matrix Biol 19: 623-629, 2000.

36 Price SJ, Greaves DR and Watkins H: Identification of novel, functional genetic variants in the human matrix metalloproteinase2 gene: Role of $\mathrm{Sp} 1$ in allele-specific transcriptional regulation. J Biol Chem 276: 7549-7558, 2001.
37 Yu C, Zhou Y, Miao X, Xiong P, Tan W and Lin D: Functional haplotypes in the promoter of matrix metalloproteinase-2 predict risk of the occurrence and metastasis of esophageal cancer. Cancer Res 64: 7622-7628, 2004.

38 Elander N, Soderkvist P and Fransen K: Matrix metalloproteinase (MMP)-1, -2, -3 and -9 promoter polymorphisms in colorectal cancer. Anticancer Res 26: 791-795, 2006.

39 Li Y, Jin X, Kang S, Wang Y, Du H, Zhang J, Guo W, Wang N and Fang S: Polymorphisms in the promoter regions of the matrix metalloproteinases- $1,-3,-7$, and -9 and the risk of epithelial ovarian cancer in China. Gynecol Oncol 101: 92-96, 2006.

$40 \mathrm{Hu}$ Z, Huo X, Lu D, Qian J, Zhou J, Chen Y, Xu L, Ma H, Zhu J, Wei $Q$ and Shen H: Functional polymorphisms of matrix metalloproteinase- 9 are associated with risk of occurrence and metastasis of lung cancer. Clin Cancer Res 11: 5433-5439, 2005.

41 Biolchini F, Pollastri G, Figurelli S and Chiarini L: Carcinogen metabolism, DNA damage repair and oral head and neck squamocellular carcinoma (HNSCC). A review. Minerva Stomatol 54: 405-414, 2005.

42 Lai KC and Lee TC: Genetic damage in cultured human keratinocytes stressed by long-term exposure to areca nut extracts. Mutat Res 599: 66-75, 2006.

43 Nagaraj NS, Beckers S, Mensah JK, Waigel S, Vigneswaran N and Zacharias W: Cigarette smoke condensate induces cytochromes $\mathrm{P} 450$ and aldo-keto reductases in oral cancer cells. Toxicol Lett 165: 182-194, 2006.

44 Bau DT, Chang CH, Tsai MH, Chiu CF, Tsou YA, Wang RF, Tsai CW and Tsai RY: Association between DNA repair gene ATM polymorphisms and oral cancer susceptibility. Laryngoscope 120: 2417-2422, 2010.
Received May 9, 2017

Revised May 22, 2017

Accepted May 23, 2017 